\title{
EL «ÚLTIMO ERROR» DE ROSA LUXEMBURG*
}

Lo más conocido, sin duda, de la teoría política de Rosa Luxemburg son sus «errores» $\mathrm{y}$, cuando menos, los tópicos que a propósito de ella han vulgarizado gran parte de sus intérpretes y críticos. Así, para los que se basan en su Acumulación del Capital, esta figura marxista aparece como exponente máximo del «fatalismo» y del «economicismo». Los que se centran, en cambio, en la lectura de Huelga de masas, partido y sindicatos afirman que ahí se hallan las bases del «voluntarismo» y de lo que se conoce como «teoría del espontaneísmo». Para otros, que prefieren La revolución rusa o Cuestiones organizativas de la socialdemocracia rusa, Rosa Luxemburg no es más que un símbolo del socialdemocratismo, del antibolchevismo, de la "vía democrática» al socialismo, y así, hasta ciento...

Son pocos los que, lejos de contentarse con este tipo de interpretaciones y lecturas parciales, han optado, en la medida de lo posible, por un conocimiento directo de lo que la revolucionaria polaca realmente escribió y por qué; única forma ésta, por lo demás, mediante la que podría irse desvelando el escandaloso desconocimiento que subyace a esa enumeración acrítica de «errores», es decir, al mito de lo que conocemos hoy como «luxemburguismo», concepto éste que ha llegado a contener tantas supuestas «desviaciones», muchas veces incluso contradictorias entre sí, que la verdadera dimensión histórico-política de la gran pensadora marxista ha sido durante mucho tiempo irreconocible.

El «luxemburguismo», pues, cuyo origen debe ser buscado, en lo esencial, y entre otras varias razones, en ese desconocimiento y en la utilización - para fines políticos concretos- de aspetos parciales, descontextualizados, de su pensamiento, había llegado así a convertirse, desde su condena pública por parte de Stalin, en una especie de «sistema de errores», «sistema» que, a partir de la recuperación de la línea dialéctico-revolucionaria que supuso el Mayo francés, parecía haber entrado ya en una fase de absoluta liquidación.

* Reproducido de Materiales, 3 (mayo-junio 1977). 
Pero ahora, sorprendentemente, se vuelve no sólo a levantar la liebre de este mítico «sistema», sino que, además, éste viene ampliado con un «último error»: el de no haberse ocupado de la emancipación de la mujer, como se afirma de Rosa Luxemburg en La mujer y la guerra civil española. ${ }^{1}$ $\mathrm{Si}$ bien hay que reconocer el indudable mérito de la autora de este libro por su meticulosa labor de investigación, pionera en este tema sobre la mujer durante nuestra contienda civil, y por su preocupación por dar a conocer, de alguna manera, a esta teórica marxista, creemos sinceramente, por los motivos que expondremos, que hubiera sido muchísimo más coherente, dadas las coordenadas y los objetivos que se plantea la autora, no incluir en la obra la breve nota biográfica sobre Luxemburg. En primer lugar, porque ésta no fue, obviamente, una «feminista» en el sentido más actual del término, como así lo explicita ya la autora. Y en segundo lugar, porque esa nota biográfica, de apenas siete páginas, arroja un balance, una vez más, tan negativo y confuso sobre su ya compleja existencia y su mal conocido pensamiento, y contiene tal cantidad de errotes, que apenas podemos reconocer al personaje reseñado en esas líneas, con lo que se juega, o se cuenta de antemano, parece, con la ignorancia del lector.

Matizando un poco más sobre la naturaleza de los errores que contienen esas breves páginas, vemos que, aparte de algunos de tipo secundario, anecdótico - por ejemplo: Luxemburg nunca tuvo una "cátedra» de Economía en la Escuela Obrera en Suiza (p. 64), sino que tomó a su cargo las clases de Economía en la Escuela que el partido alemán abrió en Berlín; no luchó «en sus últimos años contra la Primera Guerra Mundial» (p. 65), sino que trabajó siempre contra la guerra, el imperialismo y el militarismo en general; no fue encarcelada por primera vez en 1918 (p. 65), sino en 1904, o quizá ya antes; no existe, que sepamos, evidencia alguna de colaboraciones suyas en el diario Nacbala fundado por Trotsky (p. 65); no es cierto que no abunden datos biográficos sobre ella (p. 66), pues existen hoy nada menos que tres importantes biografías-, ', hay otro tipo de errores que desbordan la anécdota para entrar de lleno en la línea del más puro y ortodoxo «luxemburguismo». A título de ejemplo:

1. El hecho de que Luxemburg se afirmara en sus concepciones an-

1. Carmen Alcalde, La mujer y la guerra civil española (Madrid: Ed. Cambio 16, 1976).

2. J. P. Nettl, Rosa Luxemburg (México: Era, 1974); P. Frölich, Rosa Luxemburg. Vida y obra (Madrid: Fundamentos, 1976); G. Badía, Rosa Luxemburg (París: Ed. Sociales. 1975). 
tirreformistas y revolucionarias no fue un mero producto de la reflexión durante sus meses de cárcel (p. 65), pues estas concepciones constituyeron, puede afirmarse sin vacilaciones, ni más ni menos que el leit motiv de toda su vida y obra. Ahí está, sino, su Reforma social o Revolución -escrita nada menos que en 1898-, una de sus obras clave, en la que se analiza por primera vez desde una óptica revolucionaria el alcance real de la «revisión» emprendida por Bernstein de la obra de Marx, y, por ende, la naturaleza no marxista, antiobrera, de la opción reformista.

2. La afirmación de «la afinidad y atracción que Rosa sentía por Trotsky» (p. 65) con que tan gratuitamente nos obsequia Carmen Alcalde, no sólo convendría matizarla más, sino que está desmentida por la propia Rosa en su correspondencia (es conocida la mutua antipatía que ambos marxistas se profesaron en vida). Afirmaciones de esta índole son el pilar básico sobre el que se asienta parte del mito «luxemburguista», tal y como lo definió Stalin. Puede decirse, de paso, que la concépción luxemburguiana de las etapas de la revolución tiene mayor similitud con la concepción leninista que con la «teoría de la revolución permanente». Pero en cualquier caso es un tema lo suficientemente amplio, complejo e importante como para dedicarle algo más que una simple frase.

3. Luxemburg nunca afirmó que la consigna leninista del «derecho de las naciones a la autodeterminación» fuera «reaccionaria» (p. 70), sin más (véase si no su apoyo a la autodeterminación de los pueblos sometidos al Imperio Otomano). Aunque sí empleó en más de una ocasión ese calificativo, en su polémica con Lenin sobre esta cuestión, intervinieron tantos factores - hasta ahora poco o mal conocidos-, que no nos parece hoy ya lícito zanjar el asunto con simples etiquetas o citas descontextualizadas. Pero quizá convenga matizar aquí que lo que Luxemburg sí cuestionaba era el uso demagógico de conceptos tales como «pueblo», «nación» o «libertad» que, en la mayoría de casos, eran utilizados para encubrir -y sustituir- Ia realidad de la Iucha de clases. Ésta fue una de Ias muchas razones que la llevaron a oponerse a la lucha por la reconstrucción de un estado polaco independiente, y no por ello «terminó afiliándose al partido socialdemócrata ruso», como parece desprenderse de las líneas biográficas que comentamos (p. 65), puesto que a ese partido pertenecía ya en calidad de miembro de la socialdemocracia polaca, que era parte integrante de la rusa...

4. No tiene absolutamente ningún sentido la afirmación según la cual «en la grave lucha emprendida entre bolcheviques y mencheviques Rosa Luxemburg... acude en ayuda de los mencheviques con su teoría de la espontaneidad...» (p. 69). Aparte del dato histórico de que su intervención en la mencionada polémica fue de oposición a lo que ella entendió como 
actitud de intransigencia por parte de Lenin, para conseguir algo que a sus ojos era prioritario - la unidad del partido-, con una evidente incomprensión de lo que realmente se debatía en el partido ruso - $-\mathrm{y}$ con el consiguiente apoyo indirecto a los mencheviques que esa oposición supuso-, difícilmente podía «venir en ayuda» de unas concepciones, las mencheviques, que nunca compartió - diga lo que diga Stalin-, y mucho menos con «una teoría», la de la «espontaneidad», que, de haber existido en realidad, no podría estar más lejos de las rígidas y mecánicas concepciones mencheviques.

Con todo ello Carmen Alcalde no hace sino contribuir, sin duda muy a pesar suyo, a lo que, según ella misma, habrían logrado los ideólogos «hombres»: correr un tupido y «ortodoxo» velo sobre la obra de una de las más importantes representantes de la teoría crítico-revolucionaria, haciendo así posible la pervivencia, si no la consolidación, del mito luxemburguista, en su versión más degradada.

\section{III}

Pero lo más discutible, a nuestro juicio, y que necesita de una más profunda reflexión crítica, es el nuevo tipo de utilización - $y$, por tanto, de deformación- que en La mujer y la guerra civil española se lleva a cabo de parte del pensamiento de Luxemburg, utilización que tiene su punto de partida en la óptica desde la cual se tamizan sus escritos. Nos referimos a la óptica de lo que se ha dado en llamar «feminismo radical», que parte de la conocida premisa de que la mujer es una clase. Premisa que aplicada a nuestro caso se concreta en la proposición siguiente: el error de Rosa Luxemburg fue el de «no ocuparse plenamente de la emancipación de la mujer. Sus "hermanas" - se afirma en la p. 68- le preocuparon mucho menos que sus hermanos...»!!!

$Y$ a esa premisa nos quisiéramos referit muy brevemente, puesto que guarda relación no sólo con las concepciones de algunas corrientes feministas actuales - de las que la autora de este libro se erige, en esta ocasión, en portavoz-, sino, y sobre todo, con la compleja y polémica relación que existe entre «lo político» y «lo feminista», o, más concretamente, entre marxismo y feminismo. Cuestión ésta que no pretendemos, por supuesto, analizar en profundidad, dado que no es éste ni el lugar apropiado ni el propósito central de estas líneas. Pero sí que desearíamos, con una consciente voluntad polémica, plantear algunas cuestiones que nos parecen importantes, especialmente para quienes nos consideramos feministas.

Para empezar, si con ese «último error» que se le atribuye se intenta implícitamente llegar a mostrar que el enemigo principal de esta revolu- 
cionaria polaca no fue tanto el reformismo, la burocratización progresiva de la socialdemocracia, el oportunismo político, el imperialismo y el nacionalismo estrecho, sino los «hombres», vale la pena dejar constancia de un contexto y de unos presupuestos mínimos que no sólo fueron dominantes en su pensamiento, sino que nos parecen fundamentales para clarificar la personalidad política de esta figura marxista.

En primer lugar, no se encuentra en toda la obra de Luxemburg una sola línea que pueda corroborar esa «menor preocupación por sus hermanas», pues ello remitiría a algún tipo de juicio formulado en este sentido por Rosa alguna vez, y ello no es obviamente el caso, pues ella se refería preferentemente al «proletariado», al «pueblo trabajador», etcétera, en términos generales. $Y$ esa «generalidad» obedecía directamente a la «globalidad» de la lucha por la emancipación total de ese pueblo trabajador, emancipación ésta que era la condición necesaria (aunque boy se ha demostrado insuficiente en la práctica), es decir, prioritaria, para poder acabar con todas las demás opresiones. Es en este contexto en el que deben entenderse sus colaboraciones en Die Gleicbheit -órgano de la socialdemocracia alemana editado y dirigido por y para las mujeres asalariadas. Colaboraciones que fueron regulares y copiosas (que Carmen Alcalde no menciona), y que demuestran más bien una preocupación genuina, pero cualitativamente distinta de la actual «feminista», por poner al alcance de las trabajadoras no ya temas exclusivamente «de la mujer» relativos sólo a su sexo, sino toda la gama de cuestiones políticas que las afectaban prioritariamente como parte integrante de una clase social explotada, la obrera, y también como mujeres, es decir, como mujeres asalariadas.

Pero entendámonos en eso de «clase». Para ella, como para Marx, Lenin, y tantos otros y otras, la categoría central y básica era la de clase social, entendida de forma dinámica, esto es, histórica, social y económicamente determinada -categoría determinante en el tratamiento que dio a todas las cuestiones: problema nacional, alianzas políticas del proletariado, el internacionalismo, rol del campesinado, etapas de la revolución, etcétera- y no la «clase mujer», categoría sexual-biológica, y en cualquier caso estática y abistórica.

No «leer» a Rosa Luxemburg en relación con esa categoría básica marxista supone, por un lado, no querer entender el alcance de su obra crítica y de su lucha ideológica frontal contra la clase que las condiciones económicas de esa fase histórica concreta convierten en antagónica del proletariado: la burguesía (desde la más conservadora hasta la socialdemócrata), origen y causa últimas de la explotación de asalariados y asalariadas; una clase que fue asimismo la mayormente responsable no sólo de su muerte («gestionada» por la propia socialdemocracia), sino del aplastamiento de 
la revolución alemana. Por otro lado, ese «olvido» supone colocarse a priori en una perspectiva desde la cual la enumeración de «lagunas» y «errores» resulta terriblemente fácil, y a la larga demagógica, porque desconoce, o encubre, la contrádicción existente entre la «clase social» marxista y la «clase mujer» aludida, concepto éste que se refiere a un fenómeno o hecho, por definición, «interclasista» y, por tanto, tan ambiguo y encubridor de la realidad de la existencia de clases sociales antagónicas como los conceptos de «raza», «nación» o «pueblo», cuyo uso demagógico y a la larga reaccionario Rosa Luxemburg tanto se había esforzado por denunciar.

Así, esta posición apriorística permite a Carmen Alcalde afirmar, por ejemplo, que fue su condición de mujer, «aparte de las dificultades ideológicas», la razón por la cual «se deformó hasta la caricatura el pensamiento de Rosa Luxemburg...» (p. 67). Sí resulta ciertamente caricaturesco el que aquí se afirme como «cosa aparte» algo que no fue ni accidental ni mera dificultad, sino la constante existencial, política, de su lucha. Fue precisamente esa característica radicalidad, y no otra cosa, la que hizo posible el lento proceso de «luxemburguización», esto es, de marginación y de silenciación no sólo de su pensamiento, sino de cuantos, como ella, representaban - y representan - una crítica permanente contra la progresiva derechización de la socialdemocracia primero, y la estalinización de los partidos comunistas, más tarde.

Así se entiende también que en la siguiente cita «Desde mi regreso a Rusia me siento bastante sola..., tengo conciencia como nunca antes de todo lo que hay de timorato y mezquino en el partido; pero, sin embargo, no estoy tañ preocupada como tú, porque ya he comprendido con una claridad alarmante que esas cosas y esos hombres no cambiarán mientras la situación no sea diferente...», cita que Carmen Alcalde recoge (p. 66) de un párrafo de la carta de Luxemburg a Clara Zetkin en 1907 - carta que fue escrita, por cierto, a su regreso de Rusia-, aparezca la palabra «hombres» donde debiera decir en realidad «personas» o «gente». ${ }^{3}$ Matización importante ésta, pensamos, pues de lo contrario queda no sólo descontextualizada, sino desvirtuada la preocupación fundamental que se halla en el trasfondo de estas líneas: el creciente y progresivo anquilosamiento del sector mayoritario de la socialdemocracia alemana, de los cuadros dirigentes del partido y de los sindicatos, y su opción definitiva por el parlamentarismo, etcétera, con la consiguiente paralización de las movilizaciones

3. P. Frölich, op. cit., p. 191; Rosa Luxemburg, Vive la lutte! (Correspondance 1891-1914) (París: Maspéro, 1975), p. 285; A. Laschitza-G. Radczun, «Zum Wirken Rosa Luxemburg in der deutschen Arbeiterbewegung in den Jahren der ersten Revolution in Russland», Zeitscbrift für Gescbicbtswiss, 19, 1971, 4, p. 537. (Los subrayados de la cita son nuestros.) 
de masas, en una época en la que ya se vislumbraba la posibilidad del conflicto bélico imperialista. En una época, precisamente, en que una nueva generación de burócratas (Ebert, Scheidemann) relevaban a los viejos líderes revolucionarios Bebel y Liebknecht en la dirección del partido alemán.

Así también le resulta posible a la autora afirmar que «los ideólogos que habían compartido con ella los triunfos y fracasos de la revolución cuidaron de no excederse en arrancarla del silencio en el que quedó sumida tras el martirio...» (p. 66), cuando la realidad es que fueron precisamente bombres los que intentaron clarificar las circunstancias de su asesinato (Franz Mehring, Jeo Jogiches) hasta dar, incluso, su vida, y también bombres en su mayoría los que primero se dedicaron a recoger su dispersa obra para editarla (Paul Levi, Paul Frölich, entre otros).

Parece evidente que «su error» no fue precisamente el de no haberse ocupado de la emancipación de la mujer -cosa que está todavía por analizar con más detalle-, sino el de haberse ocupado de la emancipación del proletariado, hombres y mujeres, y haber sostenido, a tal fin, una guerra sin cuartel contra la posibilidad objetiva de que la socialdemocracia se convirtiera en el nuevo y principal instrumento de integración y explotación de los asalariados (tanto «hermanos» como «hermanas») y el caráctet imperialista y estructuralmente «asexuado» de la nueva fase del capitalismo a principios de siglo.

Repetimos que hubieta sido mejor no incluir esas líneas (que no pueden llamarse ya biográficas) en un libro de estas características y enfoque, habiendo otros personajes femeninos mucho más representativos y adecuados al marco, objetivos e ideología de La mujer y la guerra civil española (como es el caso, por ejemplo, de la anarquista ruso-americana Emma Goldman, de quien, por lo menos, puede afirmarse que sí estuvo en España durante nuestra guerra civil...), en lugar de optar por la inevitable deformación del pensamiento de una revolucionaria definitivamente «no sexista», para adecuarla a las premisas y conclusiones a las que el libro aspira.

Con todo, el libro aporta importante documentación, inédita además, y cubre una serie de lagunas históricas del todo injustificadas, que hacen su lectura de todo punto necesaria, no sólo para «ellas», sino, y sobre todo, para «ellos». 